\title{
The changing face of quality in spine surgery
}

\author{
Dieter Grob · Anne F. Mannion
}

Published online: 7 July 2009

(C) Springer-Verlag 2009

The mainstays of patient care throughout the ages used to be intuition, psychology and charisma. In this environment, which was characterised by trust on the part of the patients and society, and self-confidence and dedication to the cause on the part of the clinician, considerable advances in medical therapy were made. Although some dark chapters in our recent medical history and some singular adverse events in daily practice emphasise the weakness of such a construct, at the same time the overwhelming benefits delivered to the majority are testament to its strengths. Historically, medical treatment as a whole can be considered to have been a success.

In recent years, several factors have led to a change in this construct. The basis of trust and faith on the part of the patient has diminished somewhat and given way to increasing scepticism and demands for accountability. Together with the almost unlimited access to information on the web, the relationship between doctor and patient has undergone a fundamental change. The well-meant advice from the general practitioner, in former times accepted as "the best that can be done", is nowadays analysed critically and compared with options from other sources. Whilst this approach promotes shared decision-making, which is to be encouraged, all too often these readily accessible sources of information do not reflect unbiased professional advice but, rather, personal opinions (at bestand marketing tools at worst), universally spread on the

D. Grob

Spine Center, Schulthess Klinik, Zurich, Switzerland

\section{A. F. Mannion ( $₫)$}

Spine Center Division, Department of Research and Development, Schulthess Klinik, Lennghalde 2, 8008 Zurich, Switzerland

e-mail: anne.mannion@kws.ch web and virtually impossible to validate. In this respect, educating patients such that they know how to read and interpret this type of information is crucial [4].

The medical profession-and dare we say it, spine surgery-is a unique mixture of art and science where outcomes are not always easy to assess. Many components are involved: the patient's overall satisfaction with their medical treatment, their perception of benefit derived from a specific intervention, personal and social factors, andlast but not least - the doctor's performance. Depending on the individual situation and the method of data collection used, differing results can be obtained. Undoubtedly, RCTs are the gold standard for assessing the efficacy of a given treatment; however, in reality, these high-level investigations are difficult to realise and can sometimes create ethical concerns [7]. In such circumstances, observational studies can offer a suitable alternative or complement to RCTs, contributing to the overall body of evidence [3, 8].

It may seem paradoxical, but it is the reality: the same evolution that has made educated patients more critical towards proposed medical treatments has rendered them increasingly disinclined to participate in medical "testing procedures". Randomisation is not perceived by the patient to be a method to approach the truth but rather as a sign of insecurity on the part of the doctor. Registries seem to offer a way out of this conflict. It is now clear that it is possible to implement well-designed registries in everyday clinical practice, and they can deliver reliable results [1,9]. With intelligently designed and standardised questionnaires [5, 10], and a well-organised infrastructure combined with modern information technology [11], it is possible for large spine centres to collect data from every single eligible patient. The data acquired in such circumstances can be as valuable as those collected by means of RCTs [2, 7]. The main advantages of the registry-method of data collection 
include its practicability, statistical power (large sample sizes) and-compared with RCTs, which can create a highly "unnatural" and experiment-like situation for both patient and doctor-greater generalisability to "normal practice procedures" (i.e., external validity). Voluminous data collection by registries allows us to answer some of the most relevant questions posed by the daily clinical routine. The inclusion of patients' self-rated outcome data, collected by means of questionnaires sent to the patients to complete in the comfort of their own home, guarantees an unbiased opinion on the most important aspect of our doing: patient satisfaction.

The medical world has undergone a paradigm shift and has been forced to think critically about justifying some of the practices that were, in earlier days, simply accepted. In view of the fact that medicine is not an exact science, considerable difficulties have been encountered adapting to this shift, especially in surgical fields such as spine surgery. Many of the standard evaluations that are used to assess treatment efficacy in the pharmaceutical industry are not, or are only partially, applicable in surgery: double-blind studies are impossible and RCTs are extremely difficult to perform in daily clinical practice. Nevertheless, the systematic and prospective use of outcome measurements and the implementation of quality control/improvement initiatives are of the utmost importance to embrace, in our attempts to comply with our scientific requirements and the public's demands. The complexity of medicine-and within it, the field of spine surgery-necessitates more than one means of acquiring evidence. From this perspective, a combination of RCTs and observational studies may provide the most complete information, capitalising on the specific advantages of different methods, depending on the issue in question.

The present supplement of the European Spine Journal provides an overview of the current status of quality management in the field of spine surgery. Study of its content, delivered by experts in the field, and incorporation into everyday practice of the methods it describes, should serve to reinforce the evidence base in spine surgery.

Gathering evidence should be moved to the top of our list of professional priorities. We must recognise that this focus on evidence may, at first sight, appear to create conflicts with the existing fundamental principles of medicine: humanity, intuition, and the "art" of doing the right thing, at the right time, in the right situation, for the benefit of the patient. However, we should not forget that evidence does not make decisions, people do [6], and evidence does not absolve the surgeon of responsibility; instead, it is just one of the components of clinical expertise that provides the necessary support to allow the clinician-whilst mindful of the clinical circumstances and patient preferences [6] - to make the right decision for the individual patient. The era of research-enhanced spine health care is upon us.

\section{References}

1. Ahn H, Court-Brown CM, McQueen MM, Schemitsch EH (2009) The use of hospital registries in orthopaedic surgery. J Bone Joint Surg Am 91(Suppl 3):68-72

2. Bhandari M, Morshed S, Tornetta P 3rd, Schemitsch EH (2009) Design, conduct, and interpretation of nonrandomized orthopaedic studies: a practical approach. (All) evidence matters. J Bone Joint Surg Am 91(Suppl 3):1

3. Black N (1996) Why we need observational studies to evaluate the effectiveness of health care. BMJ 312:1215-1218

4. Coulter A, Entwistle V, Gilbert D (1999) Sharing decisions with patients: is the information good enough? Bmj 318:318-322

5. Deyo RA, Battie M, Beurskens AJHM, Bombardier C, Croft P, Koes B, Malmivaara A, Roland M, Von Korff M, Waddell G (1998) Outcome measures for low back pain research. A proposal for standardized use. Spine 23:2003-2013

6. Haynes RB (2002) Physicians' and patients' choices in evidence based practice. Editorial. BMJ 324:1350

7. Hoppe DJ, Schemitsch EH, Morshed S, Tornetta P 3rd, Bhandari M (2009) Hierarchy of evidence: where observational studies fit in and why we need them. J Bone Joint Surg Am 91(Suppl 3):2-9

8. Horn SD, DeJong G, Ryser DK, Veazie PJ, Teraoka J (2005) Another look at observational studies in rehabilitation research: going beyond the holy grail of the randomized controlled trial. Arch Phys Med Rehabil 86:S8-S15

9. Morshed S, Tornetta P 3rd, Bhandari M (2009) Analysis of observational studies: a guide to understanding statistical methods. J Bone Joint Surg Am 91(Suppl 3):50-60

10. Poolman RW, Swiontkowski MF, Fairbank JC, Schemitsch EH, Sprague S, de Vet HC (2009) Outcome instruments: rationale for their use. J Bone Joint Surg Am 91(Suppl 3):41-49

11. Roder C, Chavanne A, Mannion AF, Grob D, Aebi M, El-Kerdi A (2005) SSE Spine Tango-content, workflow, set-up. Tango, a European spine registry. Eur Spine J 14:920-924. http://www. eurospine.org-Spine 